\title{
Equilíbrio fiscal em tempos de pandemia: estudo nas capitais das unidades federativas do Brasil
}

Fiscal balance in times of pandemic: a study in the capitals of the federative units of Brazil

\author{
Jéssyca Flávia Albuquerque Pereira ${ }^{1}$ \\ Alexandre Sobreira Cialdini ${ }^{2}$ \\ Marcus Vinícius Veras Machado ${ }^{3}$ \\ Francisca Francivânia Rodrigues Ribeiro Macêdo ${ }^{4}$
}

\section{RESUMO}

Este estudo tem como objetivo verificar o equilíbrio fiscal das capitais das unidades federativas do Brasil em tempos de pandemia. Para isso, realizou-se pesquisa descritiva e documental, com abordagem quantitativa dos dados. Para o cálculo do equilíbrio fiscal, foi utilizada a metodologia da Frente Nacional dos Prefeitos publicada no Anuário Multi Cidades 2020, que afere se o ente apresenta (des)equilíbrio em suas finanças. Os resultados revelaram que o primeiro bimestre de cada exercício financeiro apresentou maiores desequilíbrios; além disso, iniciativas impostas pela Lei Complementar $n^{\circ}$ 173/2020 colaboraram para a inexistência de alterações expressivas durante os bimestres analisados de um exercício para outro. Esses resultados fornecem evidências importantes para a literatura existente, além de serem relevantes para os diversos usuários das informações contábeis, como gestores e cidadãos.

Palavras-chave: Equilíbrio fiscal. Arrecadação tributária. Capitais brasileiras.

\footnotetext{
1 Especialista em Gestão Pública e Auditoria pela Universidade Vale do Acaraú (UVA). Assistente de Controladoria da Nexos Soluções Governamentais. E-mail: jessycaflavia_52@hotmail.com

2 Doutor em Administração Pública pela Universidade de Lisboa, Portugal. Auditor da SEFAZ-CE e secretário de finanças de Eusébio-CE. E-mail: cialdinialexandre@gmail.com

3 Ph.D em Higher Education pela University of Arizona (USA). Professor Associado e Pró-Reitor de Gestão de Pessoas da Universidade Federal do Ceará. E-mail: marcusmachado@ufc.br

4 Doutora em Ciências Contábeis e Administração pela Universidade Regional de Blumenau (FURB). Professora Adjunta da Universidade Estadual Vale do Acaraú (UVA). E-mail: francymacedo2011@gmail.com
} 


\section{ABSTRACT}

This study has as main purpose to verify the fiscal balance of the capitals of the federal units of Brazil in times of pandemic. In order to do that, a descriptive and documentary research was carried out with a data quantitative approach. To calculate the fiscal balance, the National Front of Mayors' methodology published in the Yearbook Multi Cities 2020 was used which measures whether the city presents an unbalance or balance in its finances. The results revealed that the first two months of each financial year presented greater imbalances; in addition, initiatives imposed by Complementary Law \# 173/2020 contributed to the absence of significant changes during the two months analyzed from one year to another. These results provide important evidence for the existing literature, besides being relevant for the various users of accounting information, such as managers and citizens.

Keywords: Fiscal balance. Tax collection. Brazilian capitals.

Recebido: 08-02-2021

Aprovado: 17-02-2021

\section{INTRODUÇÃO}

O setor público lida com necessidades diversas de toda uma população e, como tal, precisa gerir os recursos de que dispõe com maestria. Afinal, os recursos são limitados e as carências são muitas. Portanto, primar por uma gestão fiscal responsável é um dos quesitos basilares para que se possa otimizar os recursos e se pleiteie a entrega de cada vez mais serviços e bens à população.

Sabe-se, entretanto, que o ajuste fiscal é tema presente nos debates na Administração Pública brasileira há muito tempo. Giambiagi (1997) e Sodré (2002) mencionavam, ainda no início do século 20, que esse já era 
um assunto presente no debate econômico brasileiro. Giambiagi (1997) destaca que, na década de 1980, já existia entendimento de que o ajuste fiscal era requisito fundamental para a estabilização monetária.

A edição da Lei de Responsabilidade Fiscal (LRF) - Lei Complementar $n^{\circ}$ 101/2000 - é considerada um marco regulatório de importância ímpar quando o assunto é gestão fiscal e equilíbrio das contas públicas, pois, além de modificações substanciais nas regras de planejamento e controle das contas públicas, trouxe um enfoque cuidadoso sobre a disciplina fiscal.

Em verdade, a LRF pode ser considerada de grande abrangência ao regimentar dimensões voltadas ao controle das arrecadações e aos gastos governamentais. Entre outros, esse normativo propiciou uma forçosa reflexão e introspecção dos gestores, quando do seu apetite voraz pelos gastos, fazendo-os repensar a maneira com a qual lidavam com a gestão e com a aplicação de recursos públicos.

Embora seja inegável o avanço na gestão fiscal da res pública inspirada pela Lei Complementar $n^{\circ} 101 / 2000$, muitos são os desafios para se conquistar uma gestão fiscal em que perdure o equilíbrio, e os caminhos nem sempre são retos. Corroborando com a assertiva, Monteiro (2019) relata que o equilíbrio fiscal e financeiro do Estado brasileiro é um desafio histórico permanente, que requer maior capacidade de inovação no gerenciamento do gasto público e consequente aumento nos ganhos de eficiência da Administração Pública.

Ainda segundo Monteiro (2019), os ideários constantes na LRF gestão responsável dos recursos públicos e qualidade dos gastos - são valores públicos permanentes e, portanto, devem ser empreendidos com constância, e não somente nos contextos de escassez de recursos e crise econômica. Estas devem ser posturas assíduas para que se evite colocar em xeque o equilíbrio das contas públicas, assegure-se a remuneração mensal dos servidores e supra as demandas da população. 
Morais e Antonio (2020) chamam atenção para a realidade de desequilíbrio fiscal no Brasil, com gastos sistematicamente superiores às receitas. Os autores preconizam que o predomínio dessa situação pode conduzir a um refreamento das finanças públicas no atendimento das necessidades fundamentais, por exemplo: saúde, educação, moradia, saneamento etc. Caso essa previsão se concretize, ter-se-ão efeitos devastadores sobre a parcela mais pobre, visto não possuírem meios econômicos para buscar esses serviços na rede privada.

Conforme Paes-Sousa, Rasella e Carepa-Sousa (2018), o Brasil está em recessão econômica desde os anos de 2015 e 2016, demonstrando uma sutil melhora em 2017. Na ocasião, projetava-se que os baixos números se estenderiam somente até 2020 , momento em que os entusiastas acreditavam em uma retomada do crescimento no patamar de 2014, embora alertassem que o país não seria capaz de repor as perdas ocorridas no período.

Nota-se que essa projeção, infelizmente, não pode se concretizar. Até o momento, já no ano de 2021, o país encontra-se imerso no caos da pandemia do coronavírus que se alastrou mundialmente no ano de $2020 \mathrm{e}$ ainda colhe os frutos amargos do declínio da arrecadação, necessidade de gastos emergenciais e, sobretudo, perdas de milhares de vidas.

Atualmente, tem-se consciência que se evoluiu de uma recessão para uma depressão. Afinal, a recessão é encarada como uma redução do produto interno bruto (PIB) por dois ou mais trimestres consecutivos (PAULA; PIRES, 2017), ao passo que os efeitos da depressão são mais duradouros e exponencialmente maiores e mais agressivos (CHANG, 2015). O cenário de depressão, consoante Vieira (2014), é caracterizado por quedas nos níveis de emprego e na produção industrial, escassez de crédito, baixos níveis de produção e investimento, redução das transações comerciais, crise de confiança etc.

Segundo estimativas do relatório Global Economic Prospects do World Bank (2020), em julho de 2020 já havia uma perspectiva de que o 
PIB mundial teria uma queda de mais de 5\%. Para o Brasil, já era proposta uma retração de $8 \%$ no crescimento. De acordo com dados do Tesouro, até a metade do ano de 2020 a receita total já apresentava redução de $\mathrm{R} \$ 47,3$ bilhões $(31,9 \%)$ em termos reais. Isso posto, depreende-se que, agora, mais do que em outras épocas, primar por uma gestão fiscal equilibrada e consciente deve ser uma tarefa diária obrigatória para todo gestor público.

Ante o exposto, percebe-se a importância e a deferência que a temática equilíbrio fiscal possui no meio acadêmico, na Administração Pública brasileira e no cenário político mundial. Assim, surgiu o seguinte questionamento da pesquisa: qual o equilíbrio fiscal das capitais das unidades federativas do Brasil em tempos de pandemia? Para responder à pergunta da pesquisa, traçou-se como objetivo geral verificar o equilíbrio fiscal das capitais das unidades federativas do Brasil em tempos de pandemia.

A pesquisa justifica-se pela necessidade em se utilizar os escassos recursos públicos com a maior e melhor eficiência possível, principalmente diante de uma pandemia tão persistente como a do coronavírus. Consoante dados do World Bank (2020), o período da pandemia da covid-19 será uma recessão econômica mais profunda do que a crise financeira mundial (crise subprime) que se iniciou nos EUA em 2007. Na época, essa crise impactou as economias mundiais, de modo mais expressivo nos anos de 2008 e 2009, embora alguns países da Europa, ainda em 2021, estejam em fase de recuperação.

De acordo com o relatório do World Bank (2020), há previsão, inclusive, que os efeitos dessa pandemia de saúde sejam mais desastrosos do que a crise da dívida da América Latina, ocorrida nos anos de 1980. Segundo Barbosa Filho (2017), essa crise foi provocada por uma combinação de choques de oferta e demanda, devido a erros de política econômica. Em decorrência da união desses fatores, houve uma redução do crescimento da economia brasileira e um aumento das incertezas sobre a solvência das finanças públicas. 


\section{REFERENCIAL TEÓRICO}

Esta seção traz os posicionamentos teóricos e empíricos que serviram de base para o desenvolvimento da linha de raciocínio da pesquisa. Inicialmente, apresentam-se ponderações sobre a evolução do processo orçamentário brasileiro. Na sequência, estabelecem-se discussões sobre gestão fiscal e equilíbrio fiscal na administração pública. Por último, evidenciam-se estudos anteriores que abordaram a temática em análise.

\subsection{SINOPSE HISTÓRICA DAS LEGISLAÇÕES INERENTES À CONTABILIDADE PÚBLICA E AO PROCESSO DE ORÇA- MENTAÇÃO BRASILEIRA: OS CAMINHOS TRILHADOS EM BUSCA DE UMA GESTÃO FISCAL EFICIENTE}

Preliminarmente, é válido mencionar que o processo orçamentário, também conhecido como ciclo orçamentário, corresponde a: elaboração, aprovação, execução, controle, avaliação e programação de dispêndios, em seus aspectos físico e financeiro. (CASTRO, 2008). Já o orçamento público, consoante Macêdo e Lavarda (2013, p. 71), é "um instrumento norteador das ações do gestor na implantação de projetos, programas e ações", por meio do qual são atendidas as necessidades primárias e secundárias à população.

De acordo com Mendes (2008), hierarquicamente esse processo é composto por três leis ordinárias - Plano Plurianual (PPA), Lei de Diretrizes Orçamentárias (LDO) e Lei Orçamentária Anual (LOA). Em conjunto, tais leis são o pilar de construção do sistema de elaboração do orçamento.

Desde o advento da Lei $\mathrm{n}^{\circ} 4.320 / 1964$, o processo orçamentário brasileiro passou a ser mais formal e organizado. Essa importante Lei de Direito Financeiro regula a elaboração e o controle dos balanços (agora em conjunto com os dispositivos da NBCTSP 11 e do $8^{\circ}$ MCASP), além dos orçamentos da União, estados, municípios e Distrito Federal. Embora 
prescinda de alterações urgentes, possivelmente até mesmo de revogação, essa lei foi considerada um marco e promoveu um avanço substancial no processo orçamentário brasileiro, chegando a ser nominada "Estatuto das Finanças Públicas".

A Lei $n^{\circ} 4.320 / 1964$ trouxe princípios que mudaram a maneira de se tratar o orçamento público no Brasil. Por exemplo, declarou que o orçamento deveria conter a discriminação da receita e despesa, de forma a evidenciar a política econômico-financeira e o programa de trabalho do governo, respeitando os princípios de unidade, universalidade e anualidade (BRASIL, 1964). Até então, convivia-se com orçamentos paralelos e existia a prática de não expor todas as receitas e despesas de modo claro e em sua completude. Tudo isso dificultava o processo de controle e a prestação de contas. A propósito, essa lei traz direcionamentos de como e a quem compete realizar o controle interno e externo das contas públicas.

Todavia, ainda que a Lei $\mathrm{n}^{\circ} 4.320$ tenha representado um avanço significativo para o processo orçamentário e estrutural dos balanços, Soares e Scarpin (2010) relatam que, até meados da década de 1980, as finanças públicas brasileiras ainda estavam estruturalmente desorganizadas, visto que não havia ferramentas apropriadas para realizar o planejamento, a execução e o controle financeiro.

Nascimento e Novaes (2015) destacam que, alguns anos depois, em 1986, outro passo que merece destaque na evolução da contabilidade pública brasileira é a criação da Secretaria do Tesouro Nacional (STN) órgão central do Sistema de Administração Financeira Federal e do Sistema de Contabilidade Federal - representando um avanço expressivo para o fortalecimento das finanças públicas no Brasil.

Em 1988, com a promulgação da Constituição Federal (CF/1988) que está em vigor, outros avanços ocorreram em torno do processo orçamentário e do próprio orçamento público. Inclusive, houve a inserção de um novo instrumento de planejamento no rol de leis que auxiliam na construção do orçamento em si. Trata-se da Lei de Diretrizes Orçamentá- 
rias, que faz a ponte entre as multideias constantes no Plano Plurianual e o planejamento operacional (Lei Orçamentária Anual), fazendo as vezes de planejamento tático ao verificar e direcionar as prioridades do governo para o ano seguinte. Aliado a isso, a CF/1988 estabelece, ainda, direcionamentos para o PPA e a própria LOA.

Mais tarde, no ano 2000, foi instituída a Lei Complementar $n^{\circ}$ 101/2000. Essa lei, por sua vez, implementou modificações na gestão dos entes públicos para estabelecer a transparência, o planejamento, o controle e a responsabilização como pilares básicos. Consequentemente, segundo Monteiro (2019), a LRF estimulou uma gestão responsável, uma vez que estimulou o controle da gestão fiscal ao imprimir a exigência de metas, a aferição de resultados e a publicação das contas governamentais.

Além disso, Monteiro (2019) assevera que a Lei Complementar $n^{\circ}$ 101/2000 mira no fortalecimento do processo orçamentário ao estabelecer orientações acerca da elaboração, da aprovação e da implementação da LDO, da LOA e das prestações de contas. Isso posto, apresenta-se como ícone da gestão fiscal e financeira do país.

Ante o exposto, depreende-se, então, que o orçamento público compreende a previsão das receitas e a fixação de despesas, sendo, portanto, uma programação da vida econômica e financeira do Estado (OLIVEIRA; FERREIRA, 2017). Logo, o orçamento pode ser considerado um mecanismo de planejamento para a gestão e para o equilíbrio fiscal dos entes públicos.

Conquanto, não se pode deixar de mencionar um marco de importância ímpar para a contabilidade pública no Brasil: o processo de harmonização até chegar à convergência aos padrões internacionais. Deve-se ter em mente que o processo de harmonização da contabilidade pública brasileira foi motivado, entre outros fatores, porque esta encontrava-se demasiadamente imbuída de conceitos de natureza jurídica, focando no aspecto meramente orçamentário e relegando a um segundo plano a nuança patrimonial; fato este que distanciava, sobremaneira, o Brasil do cenário internacional. 
Aliado a isso, Scaliante (2020) lembra que havia desordem nos registros contábeis feitos pelas esferas, prejudicando a uniformidade e a comparação entre as unidades federativas, comprometendo, inclusive, a prestação de contas eficaz.

Castro (2016) relata que esse panorama começou a mudar com a Portaria $n^{\circ} 184 / 2008$, editada pela Secretaria do Tesouro Nacional, pois, a partir daí, a STN determinou que fossem realizadas ações para possibilitar a convergência das práticas contábeis públicas às normas internacionais de contabilidade, fazendo-se, paulatinamente, a transição de uma contabilidade orçamentária para uma contabilidade patrimonial. A STN tem um papel protagonista em todo esse processo, inclusive com as edições do Manual de Contabilidade Aplicado ao Setor Público, que traça os requisitos obrigatórios relativos ao reconhecimento, à mensuração e à evidenciação das transações e dos eventos nas demonstrações contábeis.

\subsection{GESTÃO FISCAL E EQUILÍBRIO FISCAL}

Gerir a coisa pública implica administrar os bens e patrimônios do Estado, seguindo leis específicas em prol da sociedade. De acordo com Motta (2013), Akim e Mergulhão (2015), e Silva (2019), compete à gestão pública primar pelo emprego dos recursos públicos de forma eficiente e com transparência, visando atender às demandas sociais.

Por sua vez, a gestão fiscal acarreta adequar o modus operandi do ente ao cumprimento das principais obrigações tributárias. E, no caso do setor público, o normativo que prima pelo equilíbrio fiscal é a Lei Complementar $n^{\circ} 101 / 2000$, conforme consta no art. $1^{\circ}, \S 1^{\circ}$ da LRF:

A responsabilidade da gestão fiscal pressupõe a ação planejada e transparente, em que se previnem riscos e convergem desvios capazes de afetar o equilíbrio das contas públicas, mediante o cumprimento de metas de resultados entre receita e despesas e a obediência a limites e condições no que tange a renúncia de re- 
ceita, geração de despesas com pessoal, da seguridade social e outras, dívidas consolidada e mobiliária, operação de garantias e inscrição em resto a pagar. (BRASIL, 2000)

Silva (2019) esclarece que a premência de mecanismos legais para aumentar o controle sobre a gestão pública deu-se em decorrência dos constantes desmandos e descontroles dos gestores públicos no que diz respeito às finanças públicas. Assim, conforme Cruz et al. (2018), a criação de princípios e normas para a gestão fiscal das finanças públicas exerce um papel primordial no controle dos gastos públicos, no equilíbrio fiscal e na manutenção da dívida pública em um caminho exequível.

Amorim (2019) relata que os economistas neoliberais entendem que o equilíbrio fiscal é primordial para se desenhar um cenário de solvência para a dívida pública e para a redução da taxa de juros com a qual o Estado arca. Desse modo, permitir-se-á que o país reencontre o caminho para o crescimento. Desse modo, o equilíbrio fiscal funcionaria como condição sine qua non para um horizonte de solvência das contas do governo, mitigação dos juros da dívida pública e projeção de melhorias para o setor privado, desencadeando, assim, a recuperação dos investimentos e, portanto, do crescimento (AMORIM, 2019).

\subsection{ESTUDOS CORRELATOS}

Adiante, estão evidenciados alguns estudos semelhantes à presente pesquisa, os quais também investigaram a influência da gestão e o equilíbrio fiscal. Entre eles, Miranda et al. (2018) avaliaram a qualidade da gestão fiscal dos estados que compõem a federação brasileira, abrangendo o período de 2011 a 2015. Adotaram a Metodologia do Índice FIRJAN de Gestão Fiscal (IFGF), desenvolvido pela Federação das Indústrias do Estado do Rio de Janeiro (FIRJAN) para os municípios brasileiros, porém com algumas adaptações aportadas empiricamente. 
Cruz e Afonso (2018) verificaram a relação entre os indicadores de cumprimento das metas e dos limites fiscais com variáveis representativas dos pilares planejamento, transparência e controle. O estudo utilizou dados primários de 282 municípios brasileiros, com população superior a 100 mil habitantes, no período de 2010 a 2013. Os indicadores fiscais não apresentaram relações significativas entre si e revelaram, ainda, reduzida associação com as demais variáveis representativas da gestão fiscal. Os autores inferiram que uma das razões estava na diferença entre os incentivos que os gestores públicos tinham para cumprir metas e limites fiscais, a fim de atender aos demais pilares.

Silva (2019) investigou a influência da gestão fiscal e da eficiência da gestão pública no desenvolvimento socioeconômico dos municípios cearenses. Analisaram-se os 184 municípios cearenses durante o período que compreendeu os anos de 2007 a 2013. Para isso, utilizou-se o método de Análise Envoltória de Dados. Os resultados evidenciaram que a gestão fiscal tinha influência positiva no desenvolvimento socioeconômico dos municípios cearenses, indicando que o fato de os municípios apresentarem maior aderência à LRF implicava o aumento do desenvolvimento. Também, observou-se que a eficiência geral e em suas três dimensões (educação, saúde, e emprego e renda) também apresentou efeito positivo no desenvolvimento socioeconômico, reforçando a ideia de que os municípios que contavam com uma gestão pública mais eficiente, focada em resultados e na oferta de bens e serviços à população, tendiam a apresentar maiores indicadores de desenvolvimento municipal.

Bartoluzzio e Anjos (2019) analisaram como os incentivos político-eleitoreiros influenciavam a gestão fiscal dos municípios brasileiros e seus desdobramentos nos resultados eleitorais. Nas estimações realizadas, dois achados se sobressaíram. O primeiro é que, apesar de existir um aumento nos investimentos, visíveis à população e associados pela literatura a resultados eleitorais favoráveis, os partidos reconduzidos também possuíam uma estrutura de pessoal mais sustentável e melhores condições 
de liquidez no curto prazo, com desempenhos alavancados em períodos estratégicos, como em anos eleitorais. O segundo é que, apesar de os partidos com recondução sinalizarem melhores níveis na condição fiscal nos três ciclos políticos, no período pós-eleitoral, as médias se retraem para patamares inferiores aos alcançados pela gestão no início do primeiro mandato. Portanto, embora indicassem melhores condições fiscais em anos eleitorais, o efeito da sinalização se inverteu no ano seguinte. Ao final, percebeu-se que, como o impacto das decisões da gestão não estaria disponível para o eleitorado imediatamente no período eleitoral, os políticos poderiam se utilizar de estratégias fiscais para evitar que o equilíbrio fiscal fosse prejudicado nos momentos estratégicos e postergassem o desembolso para o ano pós-eleitoral, decisão que não prejudicaria a gestão fiscal atual e o recebimento de votos.

Silva e Crisóstomo (2019) avaliaram os efeitos da gestão fiscal e da eficiência da gestão pública no desenvolvimento socioeconômico municipal dos 184 municípios cearenses, no período de 2007 a 2013. Os resultados destacaram a importância da boa gestão dos recursos públicos nos atos gerenciais, técnicos e políticos, além de identificarem haver influência positiva entre a gestão fiscal e a eficiência da gestão pública no desenvolvimento socioeconômico municipal.

Barbosa e Daher (2020) verificaram os prováveis impactos decorrentes da crise fiscal e as particularidades inerentes a essa conjuntura, tendo como amostra quatro municípios paraenses do período de 2014 a 2018. Entre os principais resultados, observaram desequilíbrios nas finanças de todas as prefeituras analisadas e a dimensão da dependência desses municípios em relação aos repasses intergovernamentais. Identificaram, também, que a alta destinação de receita para as despesas com pessoal era um dos principais problemas enfrentados pelo Poder Executivo dos municípios.

Cialdini (2020) analisou indicadores de performance fiscal dos estados brasileiros com o objetivo de identificar se o índice de esforço fiscal 
próprio melhorou a partir da Lei de Responsabilidade Fiscal, com ênfase nos estados da região Nordeste. A partir dos dados, os resultados revelaram que $85,2 \%$ dos estados apresentaram gestão fiscal em dificuldade e 7,4\% se encontram em situação fiscal crítica, enquanto apenas outros $7,4 \%$ apresentaram gestão fiscal classificada como boa. Entre as regiões, a que obteve os melhores resultados foi a Norte, enquanto a pior média está na região Sul. A média nacional ficou classificada no conceito $C$ (Gestão em Dificuldade). Os principais fatores que prejudicam a gestão fiscal dos estados correspondem ao elevado desembolso com juros e amortização da dívida, afetando, por conseguinte, a liquidez e comprometendo, consequentemente, a condição financeira dos estados. Além disso, alguns estados não respeitaram os limites impostos pela Lei de Responsabilidade Fiscal (LRF) com relação a gastos com pessoal. Constatou-se, ainda, que, quando há um bom gerenciamento do gasto com pessoal, há maiores investimentos governamentais expandindo sua estrutura de serviços.

\section{PROCEDIMENTOS METODOLÓGICOS}

Para atender ao objetivo proposto no artigo, utilizou-se pesquisa descritiva, com abordagem quantitativa dos dados, realizada por meio de pesquisa documental. Conforme Vergana (2004, p. 47) a pesquisa descritiva expõe "características de determinada população ou determinado fenômeno, podendo estabelecer correlações entre variáveis e definir sua natureza". Esta pesquisa descreveu o equilíbrio fiscal das capitais das unidades federativas do Brasil em tempos de pandemia

A pesquisa documental, segundo Gil (2008), é muito parecida com a bibliográfica, porém difere quanto à natureza das fontes. A pesquisa documental vale-se de matérias que não receberam ainda um tratamento analítico ou podem ser modificadas e ainda receber outras interpretações quando já concluídas, de acordo com os objetivos da pesquisa. 
Esta pesquisa teve como campo de estudo as capitais brasileiras, com exceção de Brasília, por esta se tratar de território autônomo pertencente ao Distrito Federal. Assim, foram utilizados como amostra vinte e seis municípios, analisados pelas cinco regiões geográficas.

A abordagem quantitativa, consoante Fonseca (2012, p. 35), "se baseia em dados mensuráveis das variáveis, procurando verificar e explicar sua existência, relação ou influência sobre outra variável". Neste estudo, utilizou-se a aplicação de fórmula para calcular o índice de equilíbrio fiscal da amostra.

Para analisar o equilíbrio fiscal das capitais brasileiras, empregou-se a metodologia do índice de equilíbrio fiscal estabelecido pela Frente Nacional dos Prefeitos. Assim, em consonância com o Anuário Multi Cidades (2020), o método de cálculo deste índice dá-se da seguinte maneira: Receita Corrente $-($ Despesa Corrente + Amortização da dívida $/$ Receita Corrente.

Os dados foram extraídos do sítio do Tesouro e do Siconfi. Para tratamento e organização dos dados, foi utilizado o Microsoft Excel. Os documentos de onde foram coletadas as variáveis que compõem o cálculo foram: Relatório Resumido da Execução Orçamentária (RREO) e Anexo I do Balanço Orçamentário.

\section{DESCRIÇÃO E ANÁLISE DOS DADOS}

Nesta seção, são apresentados os resultados que foram obtidos por meio da análise do equilíbrio fiscal das capitais brasileiras, durante os quatro primeiros bimestres dos exercícios de 2019 e de 2020.

A Tabela 1 apresenta os valores resultantes dos índices de equilíbrio fiscal das capitais brasileiras da região Norte durante o período que compreende a análise. 
Tabela 1 - Equilíbrio Fiscal da Região Norte do Brasil

\begin{tabular}{c|c|c|c|c|c|c|c|c}
\hline \multicolumn{7}{c}{$\mathbf{2 0 1 9}$} & \multicolumn{5}{c}{$\mathbf{2 0 2 0}$} \\
\hline \multicolumn{7}{c}{ Bimestres } \\
\hline Capital & $\mathbf{1}^{\mathbf{0}}$ & $\mathbf{2}^{\mathbf{0}}$ & $\mathbf{3}^{\mathbf{0}}$ & $\mathbf{4}^{\mathbf{0}}$ & $\mathbf{1}^{\mathbf{0}}$ & $\mathbf{2}^{\mathbf{0}}$ & $\mathbf{3}^{\mathbf{0}}$ & $\mathbf{4}^{\mathbf{0}}$ \\
\hline Belém & $-40,1 \%$ & $-12,3 \%$ & $21,1 \%$ & $17,0 \%$ & $-36,8 \%$ & $-34,2 \%$ & $7,9 \%$ & $41,4 \%$ \\
\hline $\begin{array}{c}\text { Boa } \\
\text { Vista }\end{array}$ & $-182,5 \%$ & $48,1 \%$ & $36,1 \%$ & $49,8 \%$ & $-184,0 \%$ & $32,6 \%$ & $22,7 \%$ & $70,8 \%$ \\
\hline Macapá & $-5,3 \%$ & $-5,1 \%$ & $5,3 \%$ & $9,2 \%$ & $-11,3 \%$ & $-27,0 \%$ & $5,4 \%$ & $18,8 \%$ \\
\hline Manaus & $-42,4 \%$ & $28,5 \%$ & $-15,6 \%$ & $17,6 \%$ & $-49,4 \%$ & $39,2 \%$ & $8,9 \%$ & $24,5 \%$ \\
\hline Palmas & $-1,3 \%$ & $4,0 \%$ & $5,3 \%$ & $39,1 \%$ & $-14,7 \%$ & $12,8 \%$ & $14,7 \%$ & $31,9 \%$ \\
\hline $\begin{array}{c}\text { Porto } \\
\text { Velho }\end{array}$ & $-153,2 \%$ & $61,7 \%$ & $55,6 \%$ & $-36,5 \%$ & $-183,8 \%$ & $62,8 \%$ & $60,3 \%$ & $-1,7 \%$ \\
\hline $\begin{array}{c}\text { Rio } \\
\text { Branco }\end{array}$ & $-4,3 \%$ & $12,3 \%$ & $31,7 \%$ & $20,4 \%$ & $-74,5 \%$ & $-5,1 \%$ & $40,9 \%$ & $39,9 \%$ \\
\hline
\end{tabular}

Fonte: Elaborada pelos autores (2020).

Nota-se, na Tabela 1, que o primeiro bimestre dos exercícios 2019 e 2020 apresentaram percentuais negativos; portanto, demonstram situação de desequilíbrio fiscal, indicando que o somatório da despesa corrente e a amortização de dívidas dos municípios foi maior do que o total da receita corrente, haja vista que o valor empenhado na despesa com amortização de dívidas durante o primeiro bimestre foi maior em relação aos demais bimestres, o que pode justificar tal fato. Desse modo, infere-se que o equilíbrio fiscal fora afetado, ferindo, assim, o art. $1^{\circ}, \S 1^{\circ}$ da Lei Complemen$\operatorname{tar} \mathrm{n}^{\mathrm{o}} 101 / 2000$, in verbis:

A responsabilidade na gestão fiscal pressupõe a ação planejada e transparente, em que se previnem riscos e corrigem desvios capazes de afetar o equilíbrio das contas públicas, mediante o cumprimento de metas de resultados entre receitas e despesas e a obediência a limites e condições no que tange a renúncia de receita, geração de despesas com pessoal, da seguridade social e outras, dívidas consolidada e mobiliária, operações de crédito, inclusive por antecipação de receita, concessão de garantia e inscrição em Restos a Pagar. 
Contudo, percebe-se, ainda, que o quarto bimestre do exercício de 2020 apresentou maiores percentuais em comparação aos demais bimestres restantes, o que indica que os municípios dispunham de uma situação fiscal mais confortável.

A Tabela 2 apresenta os valores resultantes dos índices de equilíbrio fiscal das capitais brasileiras da região Nordeste durante o período que compreende a análise, na qual é possível observar o primeiro bimestre de ambos os exercícios analisados.

Tabela 2 - Equilíbrio Fiscal da Região Nordeste do Brasil

\begin{tabular}{c|c|c|c|c|c|c|c|c}
\hline \multicolumn{7}{c}{$\mathbf{2 0 1 9}$} & \multicolumn{5}{c}{$\mathbf{2 0 2 0}$} \\
\hline \multicolumn{1}{c}{ Bimestres } \\
\hline Capital & $\mathbf{1}^{\mathbf{0}}$ & $\mathbf{2}^{\mathbf{0}}$ & $\mathbf{3}^{\mathbf{0}}$ & $\mathbf{4}^{\mathbf{0}}$ & $\mathbf{1}^{\mathbf{0}}$ & $\mathbf{2}^{\mathbf{0}}$ & $\mathbf{3}^{\mathbf{0}}$ & $\mathbf{4}^{\mathbf{0}}$ \\
\hline Aracaju & $-173,1 \%$ & $72,5 \%$ & $60,3 \%$ & $49,9 \%$ & $-214,0 \%$ & $64,4 \%$ & $53,8 \%$ & $69,7 \%$ \\
\hline Fortaleza & $7,1 \%$ & $-0,8 \%$ & $-20,0 \%$ & $3,2 \%$ & $-0,7 \%$ & $0,9 \%$ & $-16,6 \%$ & $2,1 \%$ \\
\hline João Pessoa & $-14,1 \%$ & $15,5 \%$ & $2,0 \%$ & $5,0 \%$ & $-7,0 \%$ & $16,3 \%$ & $2,9 \%$ & $23,1 \%$ \\
\hline Maceió & $4,5 \%$ & $12,8 \%$ & $-6,7 \%$ & $3,6 \%$ & $52,2 \%$ & $2,4 \%$ & $5,2 \%$ & $47,2 \%$ \\
\hline Natal & $-284,8 \%$ & $67,4 \%$ & $71,4 \%$ & $70,0 \%$ & $-273,2 \%$ & $55,6 \%$ & $72,8 \%$ & $59,8 \%$ \\
\hline Recife & $-59,3 \%$ & $20,5 \%$ & $15,2 \%$ & $20,6 \%$ & $-46,2 \%$ & $-14,3 \%$ & $27,2 \%$ & $36,9 \%$ \\
\hline Salvador & $-0,02 \%$ & $-5,0 \%$ & $9,0 \%$ & $14,7 \%$ & $-13,5 \%$ & $-3,8 \%$ & $0,7 \%$ & $7,3 \%$ \\
\hline São Luís & $-222,5 \%$ & $38,3 \%$ & $46,3 \%$ & $70,0 \%$ & $-303,5 \%$ & $50,2 \%$ & $61,9 \%$ & $87,7 \%$ \\
\hline Teresina & $-24,8 \%$ & $16,9 \%$ & $3,2 \%$ & $2,2 \%$ & $-31,3 \%$ & $4,2 \%$ & $-6,5 \%$ & $13,1 \%$ \\
\hline Fo $\%$ Elabo $\%$
\end{tabular}

Fonte: Elaborada pelos autores (2020).

Percebe-se, na Tabela 2, que os municípios que compõem a região Nordeste, à exceção de Maceió e Fortaleza, apresentaram percentuais negativos, indicando uma condição fiscal efetivamente insustentável no curto e no médio prazos que pode ser justificada pelo valor empenhado na despesa com amortização de dívidas durante o primeiro bimestre, levando em consideração que foi maior em relação aos demais bimestres.

Tal cenário não é interessante e tampouco o apregoado pela LRF, por doutrinadores e por pesquisadores que se debruçam sobre o assunto. 
Rememorando o posicionamento de Monteiro (2019), parafraseado na seção inicial deste trabalho, há de se lembrar que o equilíbrio fiscal e financeiro do Estado brasileiro é um desafio histórico permanente, em que a gestão responsável dos recursos públicos e a qualidade dos gastos devem ser empreendidos com constância. Por isso mesmo, a realidade atestada na Tabela 2 chama a atenção e causa preocupação, principalmente por se tratar de um período de escassez de recursos e de crise econômica e sanitária, ocasionados pela pandemia do coronavírus.

Ademais, constata-se, ainda, que o índice de equilíbrio fiscal dos demais bimestres apresentou comportamento semelhante em ambos os exercícios. Observa-se que, na grande maioria dos casos, os municípios apresentaram uma situação fiscal mais confortável, tendo em vista que a diferença entre as contas-correntes (receita corrente menos despesa e amortizações) foram acima de $10 \%$ ou mais da receita corrente.

A Tabela 3 traz o cenário vivenciado pela região Centro-Oeste do Brasil.

Tabela 3 - Equilíbrio Fiscal da Região Centro-Oeste do Brasil

\begin{tabular}{c|c|c|c|c|c|c|c|c}
\hline \multicolumn{7}{c}{2019} & \multicolumn{5}{c}{$\mathbf{2 0 2 0}$} \\
\hline \multicolumn{2}{c}{ Bimestres } \\
\hline Capital & $\mathbf{1}^{\mathbf{0}}$ & $\mathbf{2}^{\mathbf{0}}$ & $\mathbf{3}^{\mathbf{0}}$ & $\mathbf{4}^{\mathbf{0}}$ & $\mathbf{1}^{\mathbf{0}}$ & $\mathbf{2}^{\mathbf{0}}$ & $\mathbf{3}^{\mathbf{0}}$ & $\mathbf{4}^{\mathbf{0}}$ \\
\hline $\begin{array}{c}\text { Campo } \\
\text { Grande }\end{array}$ & $-231,0 \%$ & $59,5 \%$ & $52,1 \%$ & $83,8 \%$ & $-227,1 \%$ & $58,0 \%$ & $72,1 \%$ & $57,6 \%$ \\
\hline Cuiabá & $-132,4 \%$ & $30,5 \%$ & $-18,4 \%$ & $29,7 \%$ & $-141,4 \%$ & $0,8 \%$ & $16,3 \%$ & $29,2 \%$ \\
\hline Goiânia & $-277,3 \%$ & $30,2 \%$ & $79,2 \%$ & $29,5 \%$ & $-321,9 \%$ & $37,8 \%$ & $77,3 \%$ & $69,9 \%$ \\
\hline
\end{tabular}

Fonte: Elaborada pelos autores (2020).

Observa-se, na Tabela 3, que os valores resultantes dos índices de equilíbrio fiscal das capitais brasileiras da região Centro-Oeste apresentaram percentuais negativos, indicando um quadro muito delicado em suas finanças, uma vez que o saldo negativo das contas correntes esteve acima de $100 \%$ ou mais da receita corrente, o que denota um quadro de desequilíbrio fiscal. 
Constata-se, ainda, que o índice de equilíbrio fiscal dos demais bimestres apresentou comportamento semelhante comparando-se os anos de 2019 e 2020, em que os municípios demonstraram uma situação fiscal mais confortável, tendo por base que a diferença entre as contas-correntes (receita corrente menos despesa e amortizações) estiveram acima de $10 \%$ ou mais da receita corrente, com exceção do terceiro bimestre de 2019 e segundo bimestre de 2020 do município de Cuiabá.

A Tabela 4 apresenta os valores resultantes dos índices de equilíbrio fiscal das capitais brasileiras da região Sudeste durante o período que compreende a análise.

Tabela 4 - Equilíbrio Fiscal da Região Sudeste do Brasil

\begin{tabular}{|c|c|c|c|c|c|c|c|c|}
\hline \multicolumn{5}{|c|}{2019} & \multicolumn{4}{|c|}{2020} \\
\hline \multicolumn{9}{|c|}{ Bimestres } \\
\hline Capital & $1^{0}$ & $2^{\circ}$ & $3^{\circ}$ & $4^{\circ}$ & $1^{\circ}$ & $2^{\circ}$ & $3^{\circ}$ & $4^{\circ}$ \\
\hline Belo Horizonte & $3,3 \%$ & $-26,9 \%$ & $6,8 \%$ & $21,4 \%$ & $18,3 \%$ & $-5,9 \%$ & $-5,2 \%$ & $32,8 \%$ \\
\hline Rio de Janeiro & $-49,7 \%$ & $5,8 \%$ & $4,0 \%$ & $19,5 \%$ & $-57,0 \%$ & $13,2 \%$ & $12,9 \%$ & $16,1 \%$ \\
\hline São Paulo & $-97,4 \%$ & $26,1 \%$ & $45,1 \%$ & $27,6 \%$ & $-86,9 \%$ & $29,0 \%$ & $59,4 \%$ & $33,5 \%$ \\
\hline Vitória & $-81,1 \%$ & $-18,7 \%$ & $31,7 \%$ & $27,5 \%$ & $-88,5 \%$ & $43,8 \%$ & $22,1 \%$ & $79,7 \%$ \\
\hline
\end{tabular}

Fonte: Elaborada pelos autores (2020).

Nota-se, na Tabela 4, que, durante o primeiro bimestre de ambos os exercícios analisados, os municípios que compõem a região Sudeste, com exceção de Belo Horizonte, apresentaram percentuais negativos, indicando um quadro delicado em suas finanças, em que o saldo negativo das contas correntes correspondeu a um valor acima de $40 \%$ ou mais da receita corrente, configurando um quadro de desequilíbrio fiscal.

Percebe-se, ainda na Tabela 4, que o índice de equilíbrio fiscal dos demais bimestres apresentou resultados distintos comparando-se os anos de 2019 e 2020, apesar de a grande maioria ter apresentado situações fiscais mais confortáveis em relação ao primeiro bimestre, pois a diferen- 
ça positiva entre as contas-correntes (receita corrente menos despesa e amortizações) equivaleu a percentuais acima de $10 \%$ ou mais da receita corrente.

Diante do resultado de oscilação observado na Tabela 4, é válido mencionar a percepção de Gerigk, Clemente e Taffarel $(2010$, p. 5) de que "as melhorias da gestão pública, em seus aspectos financeiros, econômicos, sociais e de gestão dependem da correta e persistente gestão dos recursos financeiros". Em outras palavras, o zelo pela coisa pública e, sobretudo, pelo equilíbrio das contas públicas deve ser um trabalho constante e ininterrupto.

Corroborando com a linha de raciocínio estabelecida, Freitas e Teixeira (2020) relatam que o controle das disponibilidades financeiras dos entes federativos é uma situação sine qua non para que se estabeleça um comportamento compatível com o equilíbrio fiscal, calcado em esteios permanentes. Ardeo e Vilela (1996) são peremptórios ao afirmar que os desequilíbrios de curto prazo são reflexo de um gerenciamento de despesas malfeito.

Tabela 5 - Equilíbrio Fiscal da Região Sul do Brasil

\begin{tabular}{|c|c|c|c|c|c|c|c|c|}
\hline \multicolumn{5}{|c|}{2019} & \multicolumn{4}{|c|}{2020} \\
\hline \multicolumn{9}{|c|}{ Bimestres } \\
\hline Capital & $1^{\circ}$ & $2^{\circ}$ & $3^{\circ}$ & $4^{0}$ & $1^{\circ}$ & $2^{\circ}$ & $3^{\circ}$ & $4^{\circ}$ \\
\hline Curitiba & $30,0 \%$ & $6,1 \%$ & $-6,6 \%$ & $7,3 \%$ & $22,4 \%$ & $-10,4 \%$ & $-1,7 \%$ & $16,4 \%$ \\
\hline Florianópolis & $28,0 \%$ & $7,0 \%$ & $-11,9 \%$ & $-4,8 \%$ & $18,5 \%$ & $-8,7 \%$ & $-7,8 \%$ & $4,8 \%$ \\
\hline Porto Alegre & $-12,0 \%$ & $7,8 \%$ & $21,1 \%$ & $13,7 \%$ & $-15,1 \%$ & $-21,4 \%$ & $13,5 \%$ & $33,6 \%$ \\
\hline
\end{tabular}

Fonte: Elaborada pelos autores (2020).

Percebe-se, na Tabela 5, que, durante o terceiro bimestre de 2019 e o segundo e o terceiro bimestres de 2020, os municípios da região Sul empenharam os maiores valores com a despesa de amortização de dívidas, fato este que justifica as situações de desequilíbrio fiscal em suas finan- 
ças, considerando o saldo negativo das contas-correntes acima da receita corrente.

Nota-se, também, que o índice de equilíbrio fiscal dos demais bimestres apresentou resultados fiscais mais confortáveis, tendo em vista que a diferença positiva entre as contas-correntes (receita corrente menos receita e amortizações) esteve acima ou próximo de $10 \%$ da receita corrente.

Após as análises das tabelas, nota-se que todas as regiões do Brasil (de Norte a Sul) vêm registrando problemas de equilíbrio fiscal no intervalo temporal analisado, com breves momentos de aceno de recuperação, mas ainda sem solidez.

Sabe-se que o período analisado é delicado, visto que corresponde ao momento em que o país e o mundo vêm enfrentando diversos reveses ocasionados pela pandemia do coronavírus. No entanto, ainda assim deve-se procurar primar pelo equilíbrio das contas públicas e evitar-se, a todo custo, o processo de endividamento.

Muito embora a Lei Complementar $n^{\circ} 173 / 2020$, de caráter excepcional, tenha alterado (temporariamente) dispositivos constantes na Lei de Responsabilidade Fiscal e objetive uma retomada nacional no que concerne à efetividade dos serviços públicos e ao funcionamento da máquina estatal, ela também busca contingenciar gastos e suspender a assunção de algumas despesas (com concurso, por exemplo) pelo menos por um tempo, visando evitar uma corrida desregrada de gastos, desembocando no endividamento da res pública. Ou seja, os gestores públicos não podem e não devem descuidar do equilíbrio fiscal sob a bandeira das dificuldades orçamentárias e arrecadatórias promovidas pela crise na saúde.

\section{CONSIDERAÇÕES FINAIS}

O objetivo deste trabalho foi verificar o equilíbrio fiscal das capitais das unidades federativas do Brasil em tempos de pandemia. Para isso, rea- 
lizou-se pesquisa descritiva, documental, com abordagem quantitativa dos dados. Para o cálculo do equilíbrio fiscal, foi utilizada a metodologia da Frente Nacional dos Prefeitos, publicada no anuário Multi Cidades 2020, que afere se o ente apresenta (des)equilíbrio em suas finanças.

Os resultados demonstraram que, no primeiro bimestre, tanto do exercício de 2019 quanto do exercício de 2020, os indicadores de equilíbrio fiscal mostram-se negativos na grande maioria das capitais brasileiras, denotando condições fiscais efetivamente insustentáveis no curto e no médio prazos. Outro ponto que merece atenção foram os empenhos relacionados à despesa com amortização de dívidas dos municípios analisados, fator que pode ter colaborado para o resultado observado, visto terem sido maiores no início de cada exercício financeiro.

Viu-se, ainda, que as capitais das regiões Norte, Sudeste e Sul foram as que apresentaram equilíbrio fiscal mais comprometido durante o período analisado, especialmente no segundo e no terceiro bimestres do exercício de 2020, período em que ocorreu o primeiro epicentro da pandemia da covid-19 no Brasil, fato que pode justificar tal contexto.

Por outro lado, os resultados do quarto bimestre do exercício de 2020 da maioria das capitais brasileiras acenaram para uma tímida evolução da situação fiscal dos entes em análise. Nesse período, a diferença positiva entre as contas-correntes (receita corrente menos despesa e amortizações) equivaleu acima de $10 \%$ ou mais da receita corrente. Portanto, correspondeu ao intervalo de maior equilíbrio econômico durante a pandemia.

Em suma, concluiu-se que o equilíbrio das contas públicas das capitais brasileiras não estava em uma posição confortável, tranquila e coerente com os ditames da Lei Complementar $n^{\circ}$ 101/2000 no período analisado. Deve-se ter em mente que a busca do ideário por uma gestão pública responsável é um exercício diário, ainda que se esteja em uma situação positiva, quiçá quando se estiver em um período de recessão, de queda na arrecadação e de avanço nos gastos públicos para suplantar os problemas 
na saúde advindos em decorrência de uma pandemia.

Há de se internalizar que a sustentabilidade fiscal é essencial para toda a nação, órgãos e entes federativos. Afinal, como enfatiza Morais (2009), a ausência do equilíbrio fiscal ao longo do tempo repercutirá no nível de emprego, na estabilidade dos preços, no equilíbrio do balanço de pagamentos, nos investimentos para a infraestrutura e no financiamento do setor público. Então, ousa-se inferir que o caminho menos árduo e mais seguro é a busca contínua pela otimização dos recursos e responsabilidade na gestão fiscal.

Embora esses resultados sejam importantes em nível de controle social e sejam um espelho para os gestores das capitais brasileiras, há limitações. Entre elas, o fato de ter se limitado a estudar o equilíbrio fiscal das capitais brasileiras, bem como o período analisado. Destarte, recomenda-se a continuação desta pesquisa por meio da análise dos impactos em longo prazo, observados em decorrência desse período de desequilíbrio nas contas das capitais brasileiras. Além disso, convém sugerir a adição e a investigação de justificativas mais precisas no que se refere aos ingressos de receitas e aos dispêndios orçamentários, considerando a particularidade do período da pandemia, ou, ainda, pode-se estender a análise para os municípios.

\section{REFERÊNCIAS}

AKIM, É. K.; MERGULHÃO, R. C. Panorama da produção intelectual sobre a medição de desempenho na gestão pública. Revista de Administração Pública, [s. l.], v. 49, n. 2, p. 337-366, 2015.

AMORIM, R. L. C. Equilíbrio fiscal, taxa de juros e crescimento: comentários a partir de modelos simples usando contas nacionais. In: CORECON, 21., 2019, Blumenau. Anais [...]. Blumenau: Furb, Santa Catarina, 2019. 
ANUÁRIO MULTI CIDADES. Finanças dos Municípios do Brasil/ Publicação. Frente Nacional de Prefeitos. Vitória: Aequus Consultoria, 2020. v. 15.

ARDEO, V. L.; VILLELA, R. Credibilidade e a questão fiscal de estados e municípios. Revista Conjuntura Econômica, [s. l.], v. 50, n. 6, p. 26$31,1996$.

BARBOSA, O. G.; DAHER, D. M. Crise fiscal e seus impactos nas contas públicas: uma análise sobre as despesas com pessoal em municípios do Pará, às margens da BR222. In: SEMINÁRIO DE INICIAÇÃO CIENTÍFICA, 6., 2020, online, Anais [...]. Online, 2020.

BARTOLUZZIO, A. I. S.; ANJOS, L. C. M. Percepção dos cidadãos sobre os portais da transparência do governo estadual e das gestões municipais em Pernambuco. Revista da CGU, [s. l.], v. 11, n. 18, p. 19-19, 2019.

BRASIL. Lei Complementar $n^{0}$ 4320, de 17 de março de 1964. Estatui Normas Gerais de Direito Financeiro para elaboração e controle dos orçamentos e balanços da União, dos Estados, dos Municípios e do Distrito Federal. Brasília: Presidência da República, 1964. Disponível em: http:// www.planalto.gov.br/ccivil_03/leis/14320.htm. Acesso em: 7 abr. 2021.

BRASIL. Lei Complementar $n^{0}$ 101, de 4 de maio de 2000. Estabelece normas de finanças públicas voltadas para a responsabilidade na gestão fiscal e dá outras providências. Brasília: Presidência da República, 2000. Disponível em: http://www.planalto.gov.br/ccivil_03/leis/lcp/lcp101.htm. Acesso em: 7 abr. 2021.

CASTRO, M. C. C. S. Convergência das normas brasileiras de contabilidade aplicadas ao setor público aos padrões internacionais: 
análise da evidenciação pelos estados brasileiros e pelo Distrito Federal. 2016. 117 f. Dissertação (Mestrado em Ciências Contábeis) - Programa de Pós-graduação em Contabilidade e Controladoria, Universidade Federal de Minas Gerais, Belo Horizonte, 2016.

CASTRO, R. G. de. O processo orçamentário brasileiro. Disponível em: http://apostilas.netsaber.com.br/apostilas/998.doc. Acesso em: 5. fev. 2020.

CIALDINI, A. S. A Lei de Responsabilidade Fiscal: o processo de formulação e seus efeitos nos Estados brasileiros. 2019. 465 f. Tese (Doutorado em Administração Pública) - Instituto Superior de Ciências Sociais e Políticas, Universidade de Lisboa, Lisboa, 2020.

CRUZ, C. F. da; AFONSO, L. E. Gestão fiscal e pilares da Lei de Responsabilidade Fiscal: evidências em grandes municípios. Revista de Administração Pública, [s. 1.], v. 52, n. 1, p. 126-148, 2018.

DALFOVO, M. S; LANA, R. A; SILVEIRA, A. Métodos quantitativos e qualitativos: um resgate teórico. Revista Interdisciplinar Científica Aplicada, Blumenau, v. 2, n. 4, p. 1-13, 2008.

FREITAS, L. F. A.; TEIXEIRA, A. M. C. Sustentabilidade financeira e gestão fiscal responsável: estudo sobre as capitais dos estados brasileiros entre 2000-2012. Brazilian Journal of Business, [s. l.], v. 2, n. 4, p. 34163434, 2020.

GERIGK, W.; CLEMENTE, A.; TAFFAREL, M. O impacto da lei de responsabilidade fiscal sobre a gestão financeira dos pequenos municípios: o caso do Paraná. Revista de Educação e Pesquisa em Contabilidade (REPeC), [s. 1.], v. 4, n. 3, p. 44-69, 2010. 
GIAMBIAGI, F. Necessidades de financiamento do setor público: bases para a discussão do ajuste fiscal no Brasil - 1991/96. In: Texto para Discussão n. 53. Rio de Janeiro: BNDES, 1997.

GIL, A. C. Como elaborar projetos de pesquisa. 4. ed. São Paulo: Atlas, 2008.

MIRANDA, W. L. L. C; ARAÚJO, R. J. R. de; LEITE, I. F.; NOBRE, C. J. F. Avaliação da gestão fiscal nos estados brasileiros: análise no quinquênio 2011 a 2015. Revista Mineira de Contabilidade, [s. 1.], v. 19, n. 1, p. 55-67, 2018.

MONTEIRO, A. V. S. A crise fiscal na perspectiva dos gestores: análise do equilíbrio fiscal dos governos estaduais. 2019. 116 f. Dissertação (Mestrado em Administração Pública) - Programa de Mestrado Profissional em Administração Pública, Escola de Administração Pública, do Instituto de Direito Público, Brasília, 2019.

MORAES, A. S.; ANTONIO, M. O. M. Comportamento das despesas com pessoal dos municípios com maior PIB da região norte matogrossense: uma análise segundo a Lei de Responsabilidade Fiscal (LRF). Revista Científica da Ajes, [s. 1.], v. 9, n. 18, 2020.

MORAIS, A. C. de. Sustentabilidade fiscal de projetos de investimento em infra-estrutura de transportes: elementos para a construção de um modelo conceitual de aferição. 2007. 112 f. Dissertação (Mestrado em Transportes Urbanos) - Programa de Pós-graduação em Engenharia Civil e Ambiental, Universidade de Brasília, Brasília, 2007.

MOTTA, P. R. M. O estado da arte da gestão pública. Revista de Administração de Empresas, São Paulo, v. 53, n. 1, p. 82-90, 2013. 
NASCIMENTO, J. O.; NOVAES, R. C. S. A evolução histórica da gestão de custos no setor público: da Lei no 4.320/64 à NBCT 16.11 (Resolução CFC 1366/11): aplicação no ministério da saúde. Revista Liceu On-Line, [s. 1.], v. 5, n. 2, p. 30-49, 2015.

OLIVEIRA, C. L. de; FERREIRA, F. G. B. C. O orçamento público no Estado constitucional democrático e a deficiência crônica na gestão das finanças públicas no Brasil. Sequência, [Florianópolis], n. 76, p. 183-212, 2017.

PAES-SOUSA, R.; RASELlA, D.; CAREPA-SOUSA, J. Política econômica e saúde pública: equilíbrio fiscal e bem-estar da população. Saúde em Debate, [s. 1.], v. 42, p. 172-182, 2018.

PRODANOV, C. C.; FREITAS, E. C. de. Metodologia do trabalho científico: métodos e técnicas da pesquisa e do trabalho acadêmico. 2. ed. Novo Hamburgo: Associação Pró-Ensino Superior em Novo Hamburgo ASPEUR Universidade Feevale, 2013.

SANTOS, G. C. Aumento na dívida da Prefeitura Municipal de Patos de Minas: vista sobre a Lei de Responsabilidade Fiscal (LRF). RAGC, [s. 1.], v. 4, n. 11, 2016.

SCALIANTE, F. A. Sistema e processo orçamentário para o desenvolvimento local: estudo comparativo entre Brasil e Portugal. 2020. 215 f. Dissertação (Mestrado em Planejamento e Governança Pública) - Programa de pós-graduação em Planejamento e Governança Pública, Universidade Tecnológica Federal do Paraná, Curitiba, 2020. 
SILVA, C. R. M. da; CRISÓSTOMO, V. L. Gestão fiscal, eficiência da gestão pública e desenvolvimento socioeconômico dos municípios cearenses. RAP: Revista Brasileira de Administração Pública, [s. l.], v. 53, n. 4, 2019.

SOARES, M.; SCARPIN, J. E. A convergência da contabilidade pública nacional às normas internacionais e os impactos na aplicação da DRE na administração direta. Revista Catarinense da Ciência Contábil, [s. l.], v. 9, n. 27, p. 25-42, 2010.

SODRÉ, A. C. A. Lei de responsabilidade fiscal: condição insuficiente para o ajuste fiscal. RAE Eletrônica, [s. l.], v. 1, n. 2, p. 2-15, 2002.

VERGARA, S. C. Projetos e relatórios de pesquisa em administração. São Paulo: Atlas, 2004. 